\title{
Carp Ovarian Cystatin Binds and Agglutinates Spermatozoa via Electrostatic Interaction
}

\author{
Shun-Chang Wang',3 and Fore-Lien Huang ${ }^{1,2,4}$ \\ Institute of Biological Chemistry, ${ }^{2}$ Academia Sinica, Taipei, Taiwan \\ Institute of Biochemical Science, ${ }^{3}$ National Taiwan University, Taipei, Taiwan \\ Department of Zoology, ${ }^{4}$ National Taiwan University, Taipei, Taiwan
}

\begin{abstract}
A sperm-agglutinating factor was purified from ovulated carp eggs and the conditioned medium (CM) of cortical-reacted eggs. It was identified to be the carp ovarian cystatin. Three cystatin isoforms were found. The cystatin isolated from the CM had a higher sperm-agglutinating activity than that isolated from eggs, although the cystatins have identical $\mathrm{N}$-terminal amino acid sequences, masses, and positive charges. Differences in sperm-agglutinating activity between the cystatins of the $\mathrm{CM}$ and eggs may be caused by the different conformations because they differed in circular dichroism spectrum and tryptic map. Cystatin was discharged from cortical granules to the perivitelline space after fertilization and is abundant in the perivitelline fluid (PVF) of early stage embryos. Cystatin rapidly agglutinated spermatozoa via an electrostatic interaction. Other basic proteins also agglutinated carp spermatozoa. Their activities were inhibited by salt and high $\mathrm{pH}$. Cystatin bound to the entire surface of carp spermatozoa. The PVF of early embryos agglutinated carp spermatozoa. The activity was related to the cystatin content and influenced by ionic strength and $\mathrm{pH}$. Therefore, cystatin is the major sperm-agglutinating factor of PVF. Owing to the rapid action of cystatin on spermatozoa agglutination and the presence of a high concentration of cystatin in PVF, cystatin is considered important for preventing polyspermy in carp eggs.
\end{abstract}

fertilization, gamete biology, ovary, ovum, sperm

\section{INTRODUCTION}

Embryonic development starts at fertilization. Sperm and eggs are equipped with special apparatuses that allow them to contact, bind, and fuse with each other. The sperm of most species of animals contain an acrosome that discharges its content when the sperm contact or bind with the egg, the so-called acrosomal reaction. The hydrolytic enzymes discharged from the acrosome dissolve the vitelline layer or zona pellucida of the egg to create a path for the entrance of the sperm into the egg. Eggs have sperm receptors to bind the sperm and molecules to trigger the acrosomal reaction.

Monospermy is the general rule of fertilization in animals, although exceptions are found in a few species. Polyspermy is disastrous to embryonic development and should be prevented. Generally, there are two mechanisms involved in preventing polyspermy, the fast block and the slow block. The fast block involves changes of the mem-

\footnotetext{
'Correspondence: Fore-lien Huang, Institute of Biological Chemistry, Academia Sinica, P.O. Box 23-106, Taipei, Taiwan. FAX: 88622363 5038; e-mail: flhuang@ccms.ntu.edu.tw
}

Received: 10 October 2001

First decision: 2 November 2001.

Accepted: 28 November 2001.

(C) 2002 by the Society for the Study of Reproduction, Inc.

ISSN: 0006-3363. http://www.biolreprod.org brane potential that prevents newly fertilized eggs from fusing with a second sperm $[1,2]$. The fast block is transient and overlaps briefly with the slow block. Fertilization brings about a cortical reaction. During the cortical reaction, hydrolytic enzymes are discharged from cortical granules that modify the structures of sperm receptors. The sperm receptors are inactivated; thus, fertilized eggs cannot be fertilized again $[2,3]$.

The structures of the sperm and eggs of teleost that are involved in fertilization are somewhat different from those of other animals. The sperm of teleost lack an acrosome to pierce the chorion, the extracellular matrix surrounding fish eggs $[4,5]$. Sperm have to pass through the only path, the micropyle, to enter an egg $[4,6]$. In fish, the chorion acts as a barrier to prevent polyspermy. Removal of the chorion can cause polyspermy [7, 8]. In addition to the barrier function of the chorion, other polyspermy-preventing mechanisms have been reported in several species of fish.

The micropyle is considered critical for preventing polyspermy by limiting the number of sperm entering an egg. In certain species, the micropylar aperture is just wide enough for one sperm [2]. However, this is not the general rule. In some species, the aperture of the micropyle is wide enough to admit more than one sperm simultaneously [4, 9]. Obviously, other mechanisms are required to prevent polyspermy in this case.

A fertilization cone is formed in many species of fish, including medaka [10, 11], chum salmon [12], paddle fish [13], and carp [4, 14] but not in tilapia [9]. In carp, the fertilization cone appears $15 \mathrm{sec}$ after fertilization in the micropylar canal. During formation, the fertilization cone expels the supernumerary sperm present in the micropylar canal and plugs the micropylar canal to block additional sperm from entering. The fertilization cone retracts $1 \mathrm{~min}$ after fertilization [14]. Therefore, fertilization cones function transiently to prevent polyspermy during the early phase of fertilization.

As in other species of animals, fertilization brings about cortical reactions in fish eggs. The discharged cortical granular contents cause water uptake that results in the formation of a perivitelline space (PVS). A few sperm enter the PVS after retraction of the fertilization cone but are agglutinated and trapped in the PVS [4, 10]. Ginsburg [15] found that introduction of sperm into the PVS of trout eggs from which the perivitelline fluid (PVF) had been washed off causes polyspermy. The PVF agglutinated spermatozoa; however, this agglutinating activity was destroyed by proteinase pretreatment [15]. These findings suggest that the PVF of fish eggs contains a sperm "agglutinin" that is proteinaceous in nature and important in preventing polyspermy [2].

As found in trout eggs, the PVF of carp eggs agglutinates carp sperm [4]. We purified the sperm-agglutinating factor from ovulated carp eggs and from the conditioned 
medium (CM) of cortical-reacted eggs. This factor was identified to be cystatin. Cystatin rapidly induced sperm agglutination via an electrostatic interaction. The cystatin content in PVF was high during the early stage of fertilization. Because of its rapid action on sperm agglutination and its high content in PVF, we consider cystatin to be the major sperm-agglutinating factor of PVF that aids in the prevention of polyspermy in carp.

\section{MATERIALS AND METHODS}

\section{Chemicals}

Papain and trans-epoxy-succinyl-L-leucylamido-(4-guanidino)butane (E64) were purchased from Calbiochem Novabiochem Corp. (San Diego, CA). The benzoyloxycarbonyl-Phe-Arg-(7-amido-4-methylcoumarin) (ZPhe-Arg-MCA) was from Bachem AG (Bubendorf, Switzerland). All other chemicals were purchased from Sigma Chemical Co. (St. Louis, MO).

\section{Preparation of $\mathrm{CM}$}

Common carp (Cyprinus carpio) were purchased from a local market. Ovulation was induced by a single i.p. injection of Ovaprim (Syndel International Inc., Vancouver, BC, Canada) at a dose of $0.5 \mathrm{ml} / \mathrm{kg}$ body weight. Eggs were artificially activated by immersion in four volumes (w/ v) of distilled water for $30 \mathrm{~min}$. The cortical reaction medium was collected and centrifuged at $15000 \times g$ for $15 \mathrm{~min}$ to remove cell debris and insoluble materials. The supernatant was denoted as the CM.

\section{Collection of PVF}

Insemination was conducted by mixing carp semen and eggs without adding water. The inseminated eggs were distributed evenly on Petri dishes (Alpha Plus Scientific Co., Taoyuan, Taiwan) and immersed in tap water. The PVF was aspirated by a micromanipulator (MN-153/IM300; Narishige Co., Tokyo, Japan) and stored at $-80^{\circ} \mathrm{C}$ until use.

\section{Purification of Cystatin}

Cystatin was purified from two sources: ovulated eggs and the CM. Eggs were homogenized in 10 volumes (w/v) of extraction buffer $(50 \mathrm{mM}$ $\mathrm{NaCl}, 0.1 \%$ Triton $\mathrm{X}-100,50 \mathrm{mM}$ Tris- $\mathrm{HCl}, \mathrm{pH} 8.0$ ). The homogenate was centrifuged at $10000 \times g$ for $10 \mathrm{~min}$, and the supernatant was saved. To purify cystatin from CM, CM was adjusted to the composition of the extraction buffer.

The procedures used to purify cystatin from egg homogenate and $\mathrm{CM}$ were the same. They were applied to a SP-Sephadex column $(2.5 \times 8.5$ $\mathrm{cm}$; Pharmacia Biotech, Uppsala, Sweden) equilibrated with the extraction buffer. After washing with 5 bed volumes of washing buffer $(0.1 \mathrm{M} \mathrm{NaCl}$, $0.1 \%$ Triton $\mathrm{X}-100$ and $10 \mathrm{mM}$ Tris- $\mathrm{HCl}, \mathrm{pH} 8.0$ ) and then 2 bed volumes of $10 \mathrm{mM}$ Tris- $\mathrm{HCl}(\mathrm{pH} 8.0)$, the retarded proteins were eluted with 2 bed volumes of $0.5 \mathrm{M} \mathrm{NaCl}, 10 \mathrm{mM}$ Tris- $\mathrm{HCl}$ ( $\mathrm{pH}$ 8.0). The eluate was concentrated by Amicon ultrafiltration equipped with a YM 3 membrane $\left(M_{\mathrm{r}}\right.$ cutoff, 3000; Amicon, Beverly, MA). The concentrate was applied to a Superdex 75 fast protein liquid chromatography (FPLC) column $(1.0 \times$ $30 \mathrm{~cm}$, Pharmacia Biotech) equilibrated with $20 \mathrm{mM}$ Hepes and $150 \mathrm{mM}$ $\mathrm{NaCl}, \mathrm{pH}$ 8.0. The column was eluted with the equilibrating buffer at a flow rate of $1 \mathrm{ml} / \mathrm{min}$. Two peaks, $\mathrm{S} 1$ and S2, were resolved. After a concentration by Amicon ultrafiltration, the $\mathrm{S} 2$ peak was further separated by a Mono S HR 5/5 column (Pharmacia Biotech). The column was equilibrated with $20 \mathrm{mM}$ Hepes $(\mathrm{pH}$ 8.0). After a sample was loaded, the column was washed with the equilibrating buffer. The retarded protein was eluted by a linear gradient of $\mathrm{NaCl}$ from 0 to $400 \mathrm{mM}$ in $20 \mathrm{mM}$ Hepes ( $\mathrm{pH} \mathrm{8.0)}$ performed within $20 \mathrm{~min}$ at a flow rate of $1 \mathrm{ml} / \mathrm{min}$. Three peaks were resolved and collected separately. The buffers of the collected fractions were replaced with distilled water by Amicon ultrafiltration. The purity and sperm-agglutinating activity of each purification product were analyzed (described subsequently).

\section{Expression and Refolding of Recombinant Cystatin}

A segment of cDNA containing the mature protein of cystatin [16] was inserted into a pQE expression vector (Qiagen Gmbh, Hilden, Germany) and allowed to express in Escherichia coli as described previously [17]. The $6 \times$ His-tagged recombinant cystatin was purified by TALON metal affinity resin (Clontech Lab, Inc., Palo Alto, CA). The recombinant protein was eluted by $50 \mathrm{mM} \mathrm{NaH} \mathrm{PO}_{4}, 20 \mathrm{mM}$ PIPES, and $6 \mathrm{M}$ guanidine- $\mathrm{HCl}$, $\mathrm{pH}$ 5.3.

To refold the recombinant cystatin, Tris- $\mathrm{HCl}(\mathrm{pH}$ 8.0) and dithiothreitol were added to final concentrations of $0.2 \mathrm{M}$ and $0.1 \mathrm{M}$, respectively. The mixture was stirred gently at room temperature for $1 \mathrm{~h}$, then dialyzed with $8 \mathrm{M}$ urea and $20 \mathrm{mM}$ citric acid, $\mathrm{pH}$ 4.5. After concentration by Amicon ultrafiltration, the concentrate was mixed with 200 volumes of refolding buffer $(0.5 \mathrm{M}$ guanidine- $\mathrm{HCl}, 5 \mathrm{mM}$ EDTA, $5 \mathrm{mM}$ cysteamine, $1 \mathrm{mM}$ cystamine, and $0.1 \mathrm{M}$ Tris-HCl, $\mathrm{pH}$ 8.5). Refolding was performed at room temperature for $24 \mathrm{~h}$ with gentle stirring. Finally, the refolding buffer was replaced with distilled water by Amicon ultrafiltration. The recombinant cystatin was used to induce antibodies by s.c. injection in a rabbit.

\section{Western Blot}

SDS-PAGE was prepared and performed as described by Laemmli [18]. Gels were stained with Coomassie brilliant blue R. For Western blotting, gels were blotted onto a nitrocellulose membrane (Optitran BA-S 83, $0.2 \mu \mathrm{m}$; Schleicher \& Schuell GmbH, Dassel, Germany) with a semidry blotter (Hoefer SemiPhor; Pharmacia Biotech). The blot was incubated with the antiserum against recombinant cystatin, then with a horseradish peroxidase-conjugated secondary antibody (ICN Biomedicals Inc., Costa Mesa, CA). The color was developed with $0.03 \% \mathrm{H}_{2} \mathrm{O}_{2}$, diaminobenzidine $(0.1 \mathrm{mg} / \mathrm{ml})$, and $0.05 \% \mathrm{NiCl}_{2}$.

The cystatin content of the PVF at various developmental stages was determined by Western blotting using the cystatin purified from ovulated eggs as the standard.

\section{Immunocytochemistry}

Embryos were fixed in $0.1 \mathrm{M}$ sodium phosphate buffer ( $\mathrm{pH} 7.0)$ containing $2 \%$ paraformaldehyde and $2.5 \%$ glutaraldehyde at room temperature for $1 \mathrm{~h}$. Samples were dehydrated in graded alcohols, equilibrated with alcohol:ether (1:1), and then double-embedded in celloidin-paraffin by the method of Brown [19] with a few modifications. Briefly, samples were infiltrated in 3\% celloidin dissolved in alcohol:ether (1:1) for $72 \mathrm{~h}$ twice. Next, the samples were first hardened by chloroform vapor for 10 min then by chloroform:alcohol (1:1) for $20 \mathrm{~min}$. The hardened samples were cleared in toluene for 7 min twice, and impregnated first with paraffin:toluene $(1: 1)$ for $7 \mathrm{~min}$ and then with paraffin at $58^{\circ} \mathrm{C}$ for $7 \mathrm{~min}$ twice. Samples were embedded in paraffin and sectioned at $10 \mu \mathrm{m}$ in thickness. Sections were deparaffinized and then decelloidinized sequentially by toluene, alcohol, alcohol:ether, and alcohol. The procedures of immunostaining using the antiserum against recombinant cystatin were the same as described previously [17]. The color was developed as for Western blot. The images of sections were taken with a Kodak Professional DCS 315 digital camera (Eastman Kodak Corp., Rochester, NY). The average intensities of cystatin signals in arbitrary units were analyzed with a SigmaScan Pro image analysis program (SPSS Inc., Chicago, IL).

To detect the binding sites of cystatin on spermatozoa, $40 \mu \mathrm{g} / \mathrm{ml}$ of cystatin isoform 2 from $\mathrm{CM}$ was added to spermatozoa suspended in 50 $\mathrm{mM} \mathrm{NaCl}$ and $10 \mathrm{mM}$ Tris- $\mathrm{HCl}, \mathrm{pH}$ 7.4. For the control condition, binding was performed in $200 \mathrm{mM} \mathrm{NaCl}$ and $10 \mathrm{mM}$ Tris- $\mathrm{HCl}, \mathrm{pH}$ 7.4. Spermatozoa were fixed with formalin vapor and air-dried. Cystatin was immunostained as described previously except for the use of a tetramethylrhodamine isothiocyanate (TRITC)-conjugated second antibody (Sigma).

\section{Assay of Spermatozoa Agglutination}

Agglutination of spermatozoa was assayed by two methods.

Twofold dilution method. Samples were dialyzed against the buffer consisting of $50 \mathrm{mM} \mathrm{NaCl}$ and $10 \mathrm{mM}$ Tris- $\mathrm{HCl}, \mathrm{pH}$ 7.4. To quantify the sperm-agglutinating activity, samples were diluted 2-fold serially with the dialyzing buffer or other buffers as specified. Semen was diluted to $5 \times$ $10^{7}$ spermatozoa per milliliter in goldfish Ringer solution $(125 \mathrm{mM} \mathrm{NaCl}$,

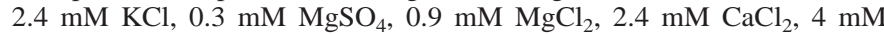
Hepes, $0.1 \%$ glucose, $\mathrm{pH} 7.5$ ). A $1-\mu 1$ aliquot of diluted semen was added to $10 \mu \mathrm{l}$ of sample. The mixture was stirred with a pipette tip and allowed to stand at room temperature for $2 \mathrm{~min}$. Agglutination of spermatozoa was examined microscopically. The sperm-agglutinating activity of a sample was expressed as the highest fold of dilution that could agglutinate spermatozoa. Before photography, spermatozoa were fixed with formalin vapor and then stained with Ehrlich hematoxylin.

Transmittance of sperm suspension. The reaction mixture $(1 \mathrm{ml})$ consisted of $20 \mu \mathrm{l}$ of $2.5 \mathrm{M} \mathrm{NaCl}$ and $500 \mathrm{mM}$ Tris- $\mathrm{HCl}(\mathrm{pH} 7.4)$ or other buffers as specified, $30 \mu \mathrm{l}$ semen containing $5 \times 10^{4}$ spermatozoa, and 
TABLE 1. Purification of cystatin from the CM of cortical-reacted eggs and ovulated eggs. ${ }^{a}$

\begin{tabular}{|c|c|c|c|c|c|c|}
\hline Source & Fraction & $\begin{array}{l}\text { Total protein } \\
(\mathrm{mg})\end{array}$ & $\begin{array}{l}\text { Specific activity } \\
\text { (dilution folds } \\
\text { per milligram) }\end{array}$ & $\begin{array}{l}\text { Relative } \\
\text { total activity }\end{array}$ & $\begin{array}{l}\text { Yield } \\
(\%)\end{array}$ & $\begin{array}{l}\text { Purification } \\
\text { fold }\end{array}$ \\
\hline \multirow[t]{6}{*}{ CM of cortical-reacted eggs } & Crude $\mathrm{CM}^{\mathrm{b}}$ & 887 & 0.4 & 355 & 100 & 1 \\
\hline & SP-Sephadex eluate & 18.7 & 20 & 374 & 105 & 50 \\
\hline & $\begin{array}{l}\text { Superdex } 75 \text { S2 } \\
\text { Mono S }\end{array}$ & 10.2 & 36 & 367 & 103 & 90 \\
\hline & M1 & 2.38 & 43 & 102 & 29 & 108 \\
\hline & M2 & 3.63 & 45 & 163 & 46 & 113 \\
\hline & M3 & 0.82 & 69 & 57 & 16 & 173 \\
\hline \multirow[t]{6}{*}{ Ovulated eggs } & Homogenate ${ }^{c}$ & 4595.4 & $\perp^{d}$ & - & - & - \\
\hline & SP-Sephadex eluate & 26.5 & 26 & 689 & 100 & 1 \\
\hline & $\begin{array}{l}\text { Superdex } 75 \text { S2 } \\
\text { Mono S }\end{array}$ & 12.2 & 20 & 244 & 35 & 0.8 \\
\hline & M1 & 1.73 & 8 & 14 & 2 & 0.31 \\
\hline & M2 & 2.24 & 7 & 16 & 2 & 0.27 \\
\hline & M3 & 1.26 & 6 & 8 & 1 & 0.23 \\
\hline
\end{tabular}

a Samples were dissolved in $50 \mathrm{mM} \mathrm{NaCl}$ and $10 \mathrm{mM}$ Tris- $\mathrm{HCl}(\mathrm{pH}$ 7.4). Sperm-agglutinating activities of samples were assayed by the 2-fold dilution method as described in Materials and Methods.

b The CM was prepared from $78 \mathrm{~g}$ of ovulated eggs that had undergone cortical reaction in distilled water for 30 min.

c Homogenate was prepared from $21.4 \mathrm{~g}$ of ovulated eggs.

d Undetectable.

$950 \mu \mathrm{l}$ of the sample in $\mathrm{H}_{2} \mathrm{O}$. After a brief stirring, the mixture was allowed to stand at room temperature for $5 \mathrm{~min}$ and was then centrifuged at $370 \times g$ for $20 \mathrm{sec}$. The top $700 \mu \mathrm{l}$ of the suspension was carefully aspirated, and the transmission at $460 \mathrm{~nm}$ was measured.

\section{Pretreatment of Spermatozoa with E64 and High Salt}

Spermatozoa were either treated with $0.1 \mathrm{mM}$ E64 at $4^{\circ} \mathrm{C}$ for $10 \mathrm{~min}$ or washed with 150 or $300 \mathrm{mM} \mathrm{NaCl}$ at room temperature for $1 \mathrm{~min} 3$ times. After treatment, spermatozoa were washed with goldfish Ringer solution and then subjected to the agglutination assay as described previously.

\section{Circular Dichroism Spectral Analysis}

The circular dichroism spectrum in the far UV region $(200-250 \mathrm{~nm})$ was acquired in a Jasco J-715 spectropolarimeter (Japan Spectroscopic, Tokyo, Japan) with a bandwidth of $1 \mathrm{~nm}$, protein concentrations of approximately $0.25 \mathrm{mg} / \mathrm{ml}$, and cells with a path length of $0.1 \mathrm{~cm}$. The buffer was $50 \mathrm{mM}$ Tris- $\mathrm{HCl}$ and $50 \mathrm{mM} \mathrm{NaCl}, \mathrm{pH}$ 7.4.

\section{Enzyme Inhibition Assay}

The apparent inhibition constant, $K_{\mathrm{i}(\text { app.). }}$, of cystatin on papain using benzoyloxycarbonyl-Phe-Arg-(7-amido-4-methylcoumarin) as substrate was determined as described by Green et al. [20]. The Michaelis constant, $K_{\mathrm{m}}$, of papain was measured by the method of Eisenthal and CornishBowden [21]. The $K_{\mathrm{i}}$ was calculated using the equation of $K_{\mathrm{i}}=K_{\mathrm{i} \text { (app.) }} /{ }^{/(1}$ $+[\mathrm{S}] / K_{\mathrm{m}}$ ) where $[\mathrm{S}]$ is the concentration of substrate.

\section{Determination of Amino Acid Composition, N-Terminal Amino Acid Sequence, Protein Content, and Mass}

Proteins were hydrolyzed with $6 \mathrm{~N} \mathrm{HCl}$ :trifluoroacetic acid $(4: 1)$ at $140^{\circ} \mathrm{C}$ for $3 \mathrm{~h}$. The amino acid composition was determined on a Beckman 6300 amino acid analyzer (Beckman Instruments Inc., Fullerton, CA). The partial N-terminal amino acid sequence was determined with a protein sequencer (477A/120A sequencer; Applied Biosystems, Foster City, CA). The protein contents were determined by the method of bicinchoninic acid [22] using BSA as standard.

For mass determination, protein was dissolved in 50\% acetonitrile and $1 \%$ acetic acid at a final concentration of $10 \mu \mathrm{M}$ and then analyzed in the electrospray ionization source of a Finnigan LCQ ion trap mass spectrometer (Finnigan MAT Instruments Inc., San Jose, CA).

\section{Peptide Mapping}

For peptide mapping, a 40- $\mu \mathrm{g}$ sample was digested with $1 \mu \mathrm{g}$ trypsin in $100 \mu \mathrm{l}$ of $50 \mathrm{mM}$ ammonium bicarbonate at $37^{\circ} \mathrm{C}$ for $2 \mathrm{~h}$. At the end of this reaction, $5 \mu \mathrm{l}$ of $1 \mathrm{M}$ dithiothreitol was added. The reaction mixture was boiled for $10 \mathrm{~min}$. The peptides were separated on an HPLC reversephase C18 column (Intersil 5 ODS-2, $4.6 \times 250$ mm; GL Sciences Inc., Tokyo, Japan). The column was eluted by a linear gradient of acetonitrile from $20 \%$ to $48 \%$ in $0.1 \%$ trifluoroacetic acid performed within $30 \mathrm{~min}$ at a flow rate of $1 \mathrm{ml} / \mathrm{min}$.

\section{Statistical Analysis}

Results were analyzed using one-way ANOVA, followed by a Bonferroni post hoc test, with Instat software (Graph Pad, San Diego, CA). Data are presented as means \pm SEMs.

\section{RESULTS}

\section{Purification of Sperm-Agglutinating Factor}

The sperm-agglutinating factor was purified from two sources, the CM of cortical-reacted eggs and ovulated eggs. The chromatography profiles of these two sources were identical on various types of columns. The results of purification are summarized in Table 1. The basic proteins of the CM and eggs isolated using SP-Sephadex column chromatography were separated by gel filtration on a Superdex 75 column. Two peaks, S1 and S2, were resolved (Fig. 1A). $\mathrm{S} 2$ was the major fraction and possessed sperm-agglutinating activity. The $\mathrm{S} 2$ of the CM had a higher sperm-agglutinating activity than that of the eggs. S2 was separated using a Mono S ion exchanger column. Three major peaks, M1, M2, and M3, were obtained (Fig. 2A). All of them had sperm-agglutinating activities. The M1, M2, and M3 of the CM had much higher sperm-agglutinating activities than those isolated from the eggs. Among the three major peaks of the CM, M3 had the highest sperm-agglutinating activity.

\section{Chemical and Physical Properties of Sperm-Agglutinating Factor}

The S2 and M1, M2, and M3 of the CM and eggs revealed a single band of $12.8 \mathrm{kDa}$ when analyzed using SDS-PAGE (Figs. 1B and 2B). The partial N-terminal amino acid sequences of M1, M2, and M3 isolated from eggs were identical respectively to those of M1, M2, and M3 isolated from the CM. Each had its own distinct sequence. 
A

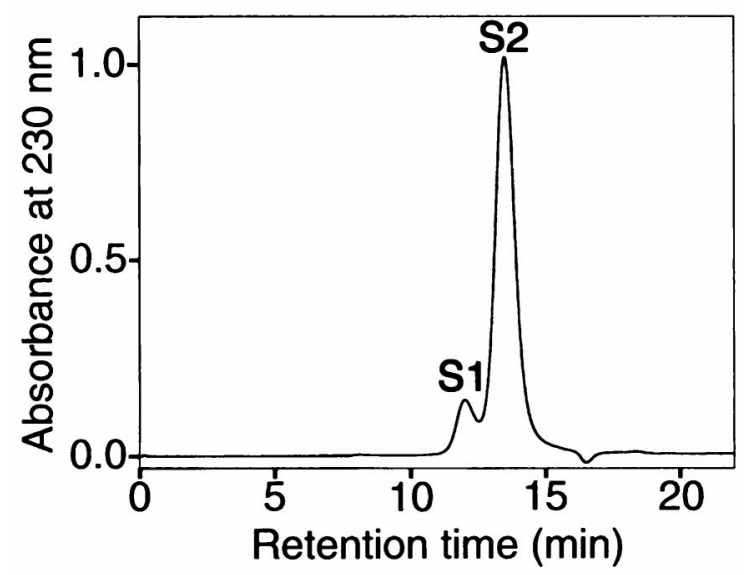

B

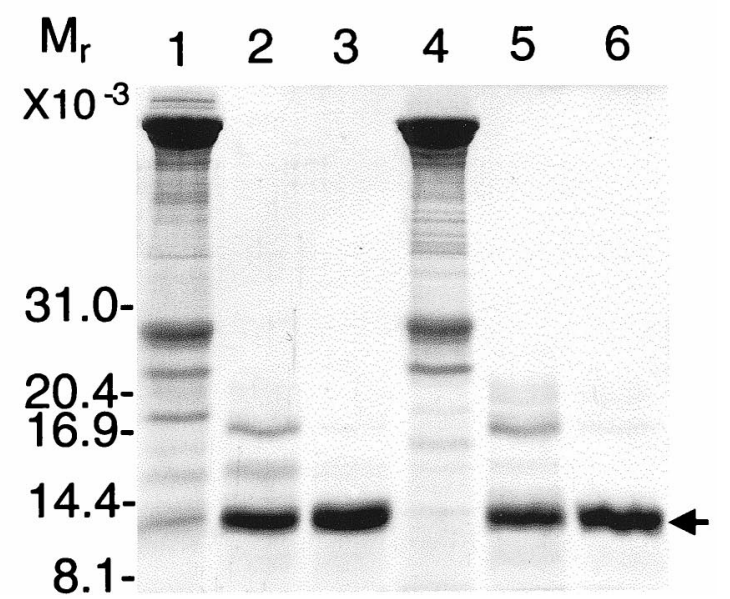

FIG. 1. Purification of the sperm-agglutinating factor. Two sources were used as the starting materials, the CM and the homogenate of ovulated eggs. Their chromatographic patterns were identical, so only the pattern from the eggs is shown. The basic proteins of the CM or eggs were isolated by SP-Sephadex column chromatography. A) Superdex 75 column chromatography of the eluate from SP-Sephadex column chromatography that contains sperm-agglutinating activities. B) SDS-PAGE. Gel was stained by Coomassie brilliant blue. Lanes 1-3, CM; lanes 4-6, ovulated eggs; lanes 1 and 4, crude extract; lanes 2 and 5, the eluate of SP-Sephadex column chromatography; and lanes 3 and 6, the S2 peak of Superdex 75 column chromatography. The amounts of samples loaded were $20 \mu \mathrm{g}$ for lanes 1 and 4 and $5 \mu \mathrm{g}$ for the rest of the lanes. The details of column chromatography are described in Materials and Methods.

However, their N-terminal amino acid sequences were similar to each other and similar to that of carp ovarian cystatin [16] (Fig. 2C). Only a few differences were found. Therefore, we considered all of the peaks to belong to cystatin. This notion was supported by the fact that the amino acid compositions of M1, M2, and M3 of eggs were similar to each other and similar to that deduced from cystatin cDNA [16] (Fig. 2D). The preceding data indicated that carp eggs contain at least 3 cystatin isoforms. We denoted M1, M2, and M3 as cystatin isoforms 1, 2, and 3, respectively. The cystatin isoform 2 of the CM and eggs had the same potency on the inhibition of papain. The inhibition constant $\left(K_{\mathrm{i}}\right)$ was $0.030 \pm 0.006 \mathrm{nM}$ for isoform 2 of eggs $(\mathrm{n}=6)$ and $0.031 \pm 0.006$ for isoform 2 of the CM $(n=7)$.

Because the cystatin isoforms isolated from the CM and eggs differed in sperm-agglutinating activities, their masses, circular dichroism spectra, and peptide maps were analyzed to see whether any structural differences existed among them. The mass of a given cystatin isoform of the egg was identical to that of the counterpart of the CM. The masses of cystatin determined using electrospray ionization mass spectrometry were 12 275, 12 244, and 12730 atomic mass units for isoforms 1, 2, and 3, respectively (Fig. 2E).

The tryptic maps of the 3 cystatin isoforms of the carp eggs were generally similar to each other and similar to those of the CM (Fig. 3). However, differences existed among them. When isoforms 1 and 2 of the eggs and CM were compared, the egg cystatins had additional peaks of $\mathrm{P}_{19.8 / 19.9}$ and $\mathrm{P}_{23.8 / 24.0}$. Note that the isoform 2 of the eggs lacked the peak of $P_{5.7}$. For the isoform 3 of the eggs and $\mathrm{CM}$, the former lacked the peaks of $\mathrm{P}_{11.3}$ and $\mathrm{P}_{11.8}$ but had an additional peak of $\mathrm{P}_{18.8}$ and a larger peak of $\mathrm{P}_{24.3 / 24.5}$. These results indicated that the cystatin of the eggs and CM was digested differentially by trypsin.

The far-UV circular dichroism spectral analysis revealed that the cystatin isoform 2 of the CM had a higher ellipticity than that of the eggs (Fig. 2F). The results indicated that the conformation of the cystatin of the CM and eggs are different. It was also noted that the refolded recombinant cystatin had a spectrum similar to that of cystatin isoform 2 of the CM. The recombinant cystatin had a similar inhibition constant on the enzymatic activity of papain $\left(K_{\mathrm{i}}=\right.$ $0.047 \pm 0.007 \mathrm{nM}$ vs. $0.030 \pm 0.006 \mathrm{nM} ; P>0.05)$ but a higher sperm-agglutinating activity (74-fold vs. 7-fold dilution per milligram of protein) than the cystatin isoform 2 of the eggs. These results indicate that the sperm-agglutinating activities of cystatin are related to the conformation but not related to the inhibition of papain.

\section{Change of Cystatin Content in the PVF During Embryonic Development}

Cystatin was stored in the cortical granules of carp eggs (Fig. 4A) and discharged into the PVS after fertilization (Fig. 4, B and C). It was detected in PVS 1 min after fertilization. The changes of cystatin content in PVS during embryonic development estimated from the results of immunocytochemical detection are shown in Figure 4D. The cystatin content reached a peak at $5 \mathrm{~min}$ after fertilization (1 vs. $5 \mathrm{~min}, P<0.001$ ) and then declined to the basal level $1 \mathrm{~h}$ after fertilization (1 vs. $1.5,2,4$, or $6 \mathrm{~h}, P>$ $0.05)$. The cystatin concentration in PVF was also measured using Western blotting (Fig. 4, E and F). The concentration was $650 \pm 50 \mu \mathrm{g} / \mathrm{ml}(\mathrm{n}=3)$ at $10-30 \mathrm{~min}$ after fertilization but declined to the basal level 6-9 $\mathrm{h}$ after fertilization.

The sperm-agglutinating activities of the PVF collected from the fertilized eggs at various developmental stages were assayed by the 2 -fold dilution method. The PVF of the eggs at 10-30 min postfertilization had considerable sperm-agglutinating activities. The specific activities were 50 -fold dilutions per milligram of cystatin as calculated from the cystatin constant of PVF, which were comparable to those of the cystatin isolated from CM (Table 1). The sperm-agglutinating activities of PVF collected from the eggs at 6-9 h postfertilization and at various intervals thereafter were undetectable. The foregoing data indicate that the sperm-agglutinating activities of PVF are related to cystatin concentration.

\section{Mechanism by Which Cystatin Agglutinates Spermatozoa}

Cystatin monomer is functioning in agglutinating spermatozoa. To agglutinate spermatozoa, cystatin either pos- 
A

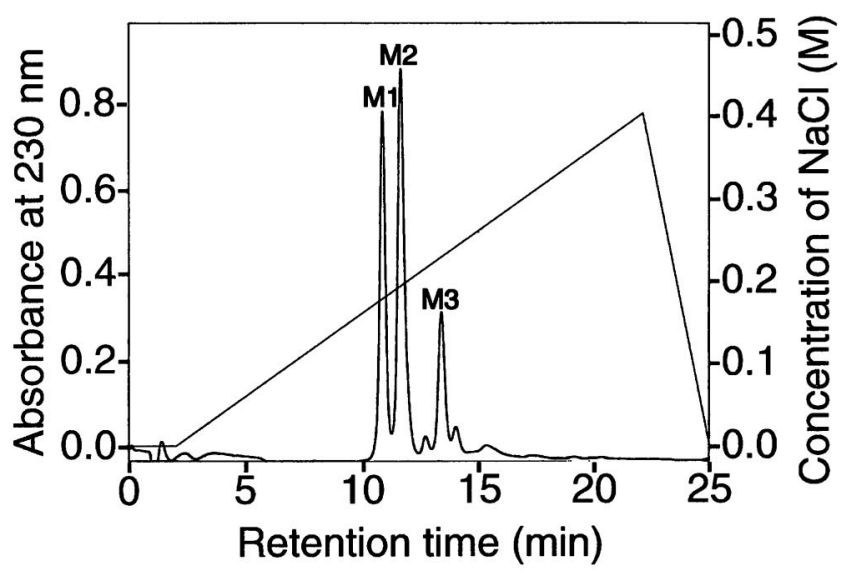

C

Cystatin

Isoform 1, CM/Egg

Isoform 2, CM/Egg

Isoform 3, CM/Egg
TGIPGGLVDADINDKDVQKA

TGIPGGLVDADINDKDVQKA

AGIPGGKVDADINDKDVQKA AGIPGGIVDADINDEDVQKA
E

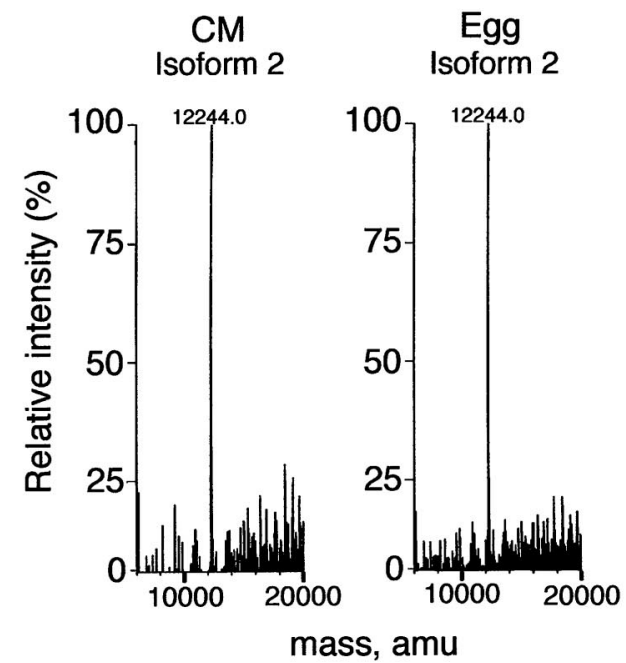

B

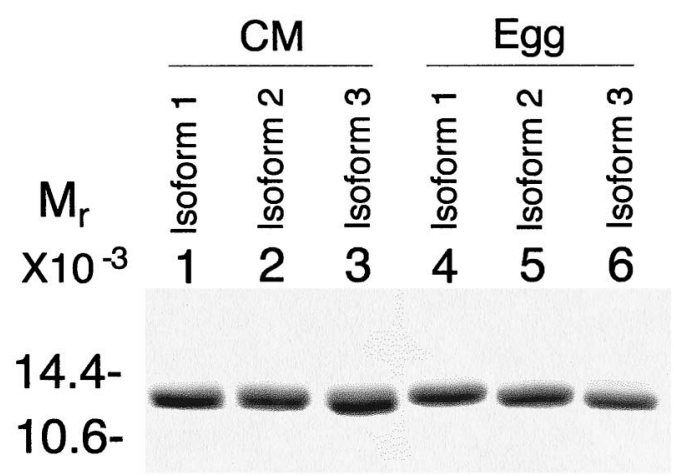

D

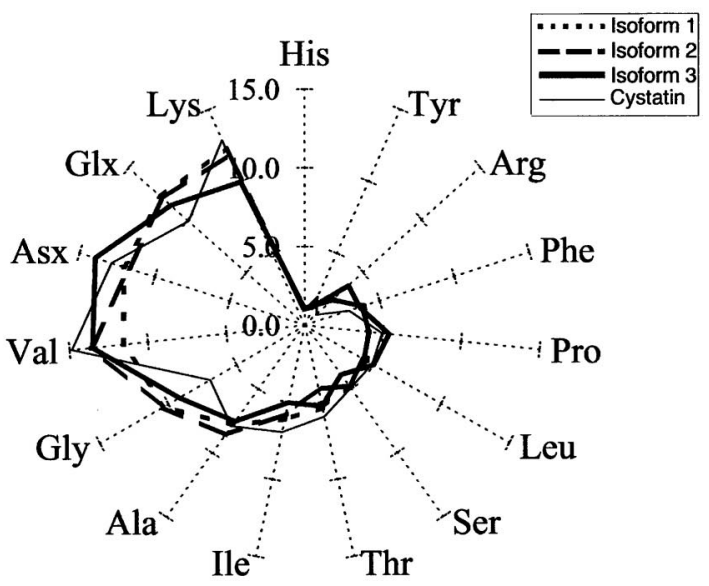

F

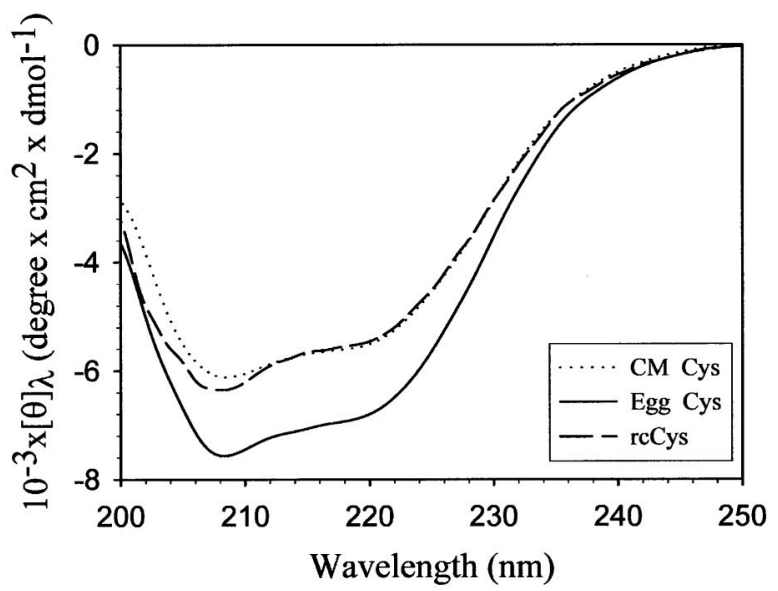

FIG. 2. Fractionation and characterization of the cystatin isoforms from ovulated eggs and the CM. A) The elution profile of the S2 peak of Figure $1 \mathrm{~A}$ on a HPLC Mono S column. The elution profiles of the CM and eggs were identical; therefore, only the pattern of the eggs is shown. Three major peaks, M1-M3, were obtained. They are denoted as cystatin isoforms 1-3, respectively. B) SDS-PAGE. Three micrograms of each isoform was analyzed. The gel was stained with Coomassie brilliant blue. C) The N-terminal amino acid sequences of isoforms 1-3 of the CM and eggs. The cystatin sequence was from Tsai et al. [16]. D) The amino acid compositions of the cystatin isoforms isolated from eggs. The composition of the cystatin was deduced from the cDNA cloned by Tsai et al. [16]. E) The mass spectra of cystatin isoform 2 of the CM and eggs analyzed by electrospray ionization mass spectrometry. Amu indicates atomic mass unit. F) The far-UV circular dichroism spectra of the recombinant cystatin (rcCys) and the cystatin isoform 2 of the CM and eggs. 


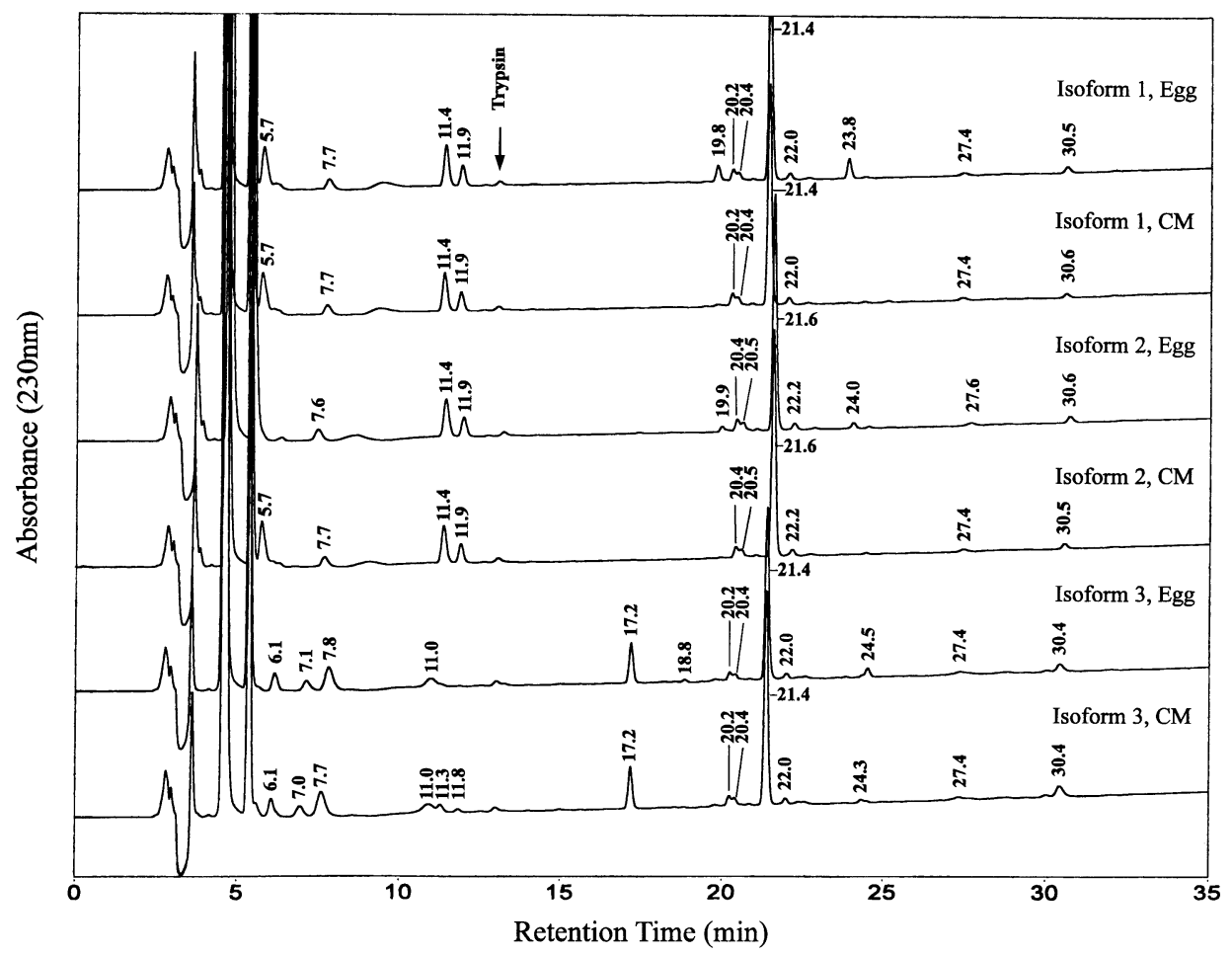

FIG. 3. The peptide maps of cystatin isoforms isolated from the CM and ovulated eggs. Forty micrograms of each isoform was digested by trypsin, and the digest was separated by a reversed phase HPLC column. The retention times of peaks are indicated. The details of the chromatography are described in Materials and Methods. sessed multiple sites or was present in the form of a multimer to bind sperm components. Gel filtration revealed that the molecular weight of the cystatin of the CM or eggs was 11700 daltons, close to the 12157 daltons predicted from cystatin cDNA [16]. Therefore, cystatin monomer was able to agglutinate spermatozoa.

Pretreatment of spermatozoa using E64 does not affect the ability of cystatin to agglutinate spermatozoa. Cystatin is an inhibitor of cysteine protease. To test whether the cysteine proteinase activity on the sperm surface is required for cystatin to induce spermatozoa agglutination, the agglutination of E64-pretreated and control spermatozoa by cystatin were compared. E64 is an inhibitor of cysteine protease. E64-pretreated spermatozoa were agglutinated as effectively as the control spermatozoa by cystatin $(P>0.05$; data not shown), which indicates that E64 does not compete with cystatin for the binding of spermatozoa.

Action of cystatin on sperm agglutination is mediated through electrostatic interaction. Carp ovarian cystatin is a basic protein with a theoretical isoelectric point $(\mathrm{pI})$ of 9.12, as calculated from the amino acid sequence deduced from cDNA. Therefore, cystatin may interact with the components of sperm electrostatically. If this hypothesis is true, other basic proteins may also agglutinate spermatozoa. Indeed, that was the case. Basic proteins, such as cytochrome $\mathrm{c}(\mathrm{p} I, 10.2)$ and histone $(\mathrm{p} I, \sim 12)$, agglutinated sperm, whereas acidic proteins, such as BSA (pI, 4.9), did not (Fig. 5). Spermatozoa were agglutinated almost instantly when cystatin, cytochrome c, or histone was added. The extent of agglutination was related to protein concentration and $\mathrm{p} I$. The higher the protein concentration used, the greater the sperm agglutination. In addition, the higher the $\mathrm{p} I$ a protein had, the smaller the amount of protein was required to agglutinate spermatozoa (Fig. 6A). The concentrations of various basic proteins needed to achieve $50 \%$ agglutination were $140 \mu \mathrm{g} / \mathrm{ml}$ for cystatin isoform 2 of the eggs, $8 \mu \mathrm{g} / \mathrm{ml}$ for cystatin isoform 2 of the CM, $11 \mu \mathrm{g} / \mathrm{ml}$ for cytochrome c, and $0.75 \mu \mathrm{g} / \mathrm{ml}$ for histone (Fig. 6A). The aggregated sperm instantaneously dissociated after the addition of $\mathrm{NaCl}$ at a concentration of $150 \mathrm{mM}$.

If the action of cystatin and other basic proteins on sperm agglutination are mediated through electrostatic interaction, then their sperm-agglutinating activities will be affected by the ionic strength and the $\mathrm{pH}$ of the assay medium. The sperm-agglutinating activities of cystatin and histone decreased as salt concentration increased (Fig. 6B). In the presence of 150 or $200 \mathrm{mM} \mathrm{NaCl}$, cystatin and histone were unable to agglutinate spermatozoa. However, spermatozoa that had been prewashed with $300 \mathrm{mM} \mathrm{NaCl}$ were agglutinated by cystatin as effectively as the control spermatozoa $(P>0.05$; data not shown). Apparently, the salt affected the interaction between the cystatin and the counterparts on the sperm surface, rather than removing the counterparts from the spermatozoa surface. The extent of inhibition of $\mathrm{NaCl}$ on sperm agglutination was expressed as the $[\mathrm{NaCl}]_{50}$, the concentration of $\mathrm{NaCl}$ required to inhibit agglutination by $50 \%$. $[\mathrm{NaCl}]_{50}$ was related to the type and concentration of the protein used. The $[\mathrm{NaCl}]_{50}$ was 60 and $80 \mathrm{mM} \mathrm{NaCl}$ for 150 and $250 \mu \mathrm{g} / \mathrm{ml}$ cystatin isoform 2 of the eggs, respectively; 80 and $140 \mathrm{mM} \mathrm{NaCl}$ for 40 and $80 \mu \mathrm{g} / \mathrm{ml}$ cystatin isoform 2 of the CM, respectively; and $110 \mathrm{mM} \mathrm{NaCl}$ for $1 \mu \mathrm{g} / \mathrm{ml}$ of histone. These results indicate that the higher the sperm-agglutinating activity a protein had and the higher the concentration of protein used, the less was the inhibition elicited by $\mathrm{NaCl}$ on spermatozoa agglutination.

The $\mathrm{pH}$ of the assay medium can also affect the ability of cystatin to agglutinate spermatozoa. The sperm-agglutinating activity of cystatin was constant when assayed from $\mathrm{pH}$ 6-9 but decreased dramatically when the $\mathrm{pH}$ exceeded 10. At $\mathrm{pH} \mathrm{10,} \mathrm{the} \mathrm{cystatin} \mathrm{isolated} \mathrm{from} \mathrm{the} \mathrm{eggs} \mathrm{was} \mathrm{un-}$ able to agglutinate spermatozoa (cystatin treated vs. control, $P>0.05$ ), whereas the cystatin isolated from the CM retained $50 \%$ of the agglutinating activities of that assayed from $\mathrm{pH}$ 6-9 (Fig. 6C). 

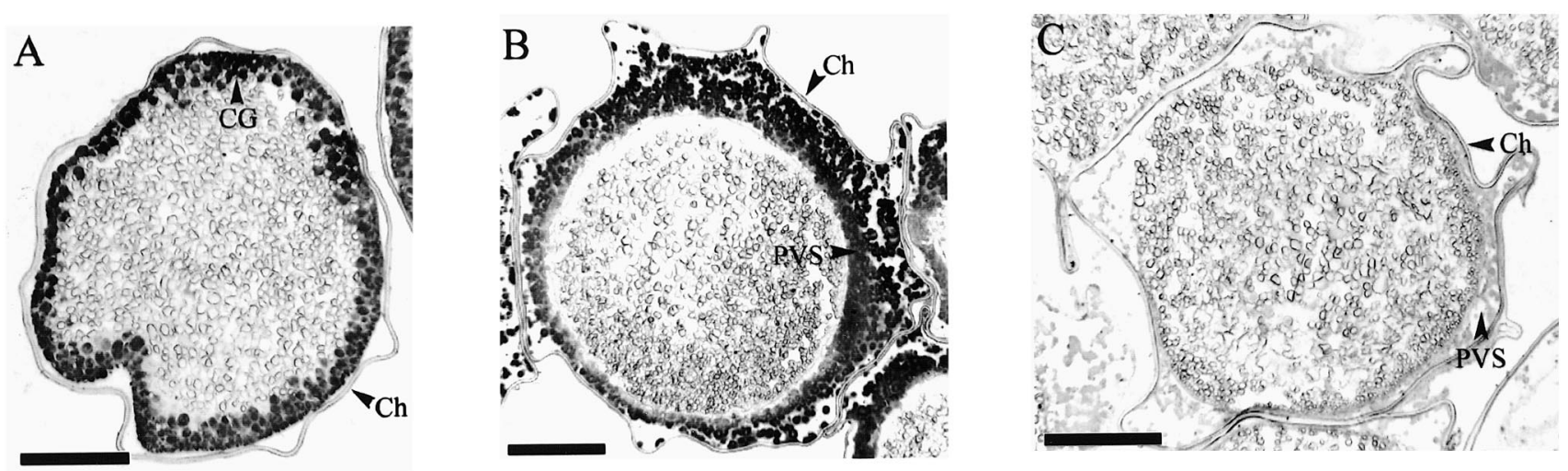

$\mathrm{D}$

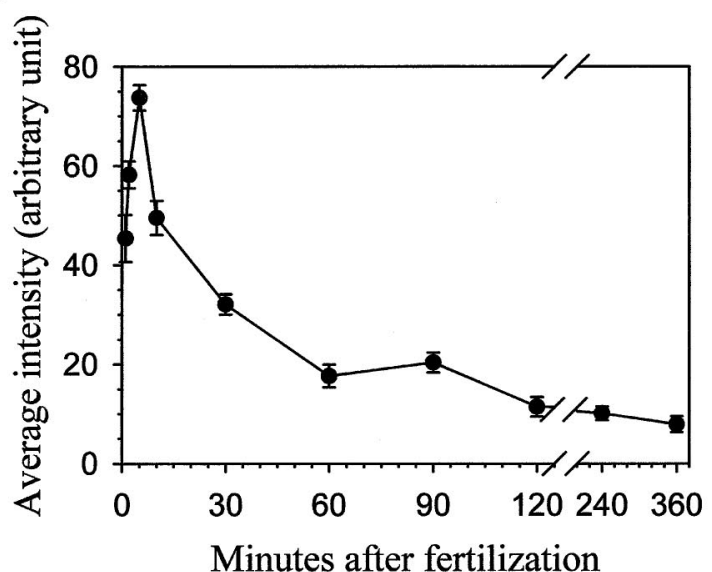

$\mathrm{E}$

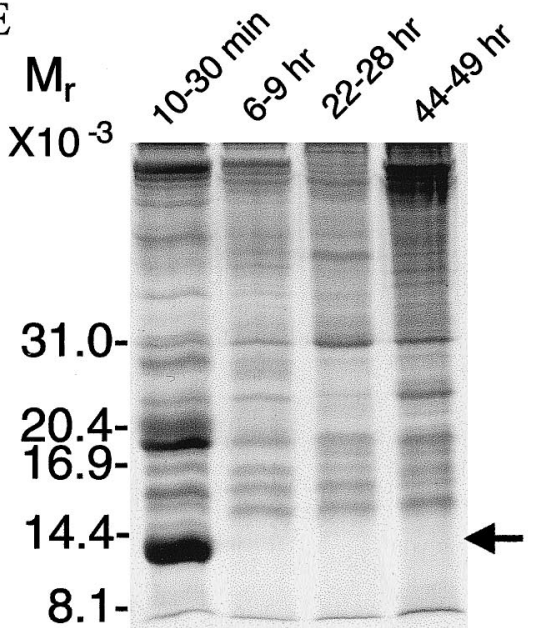

F

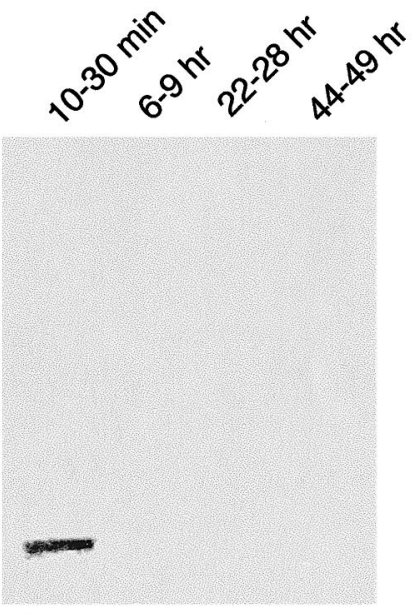

FIG. 4. The cystatin contents of the PVF from the embryos at different developmental stages. A-C) Immunocytochemical detection using an antiserum against recombinant cystatin. A) Unfertilized eggs. B) Embryo at $5 \mathrm{~min}$ after fertilization. C) Embryo at $2 \mathrm{~h}$ after fertilization. Bar $=0.3 \mathrm{~mm}$. CG, Cortical granules; Ch, chorion; PVS, perivitelline space. D) The relative contents of the cystatin in the PVS. The cystatin contents were estimated from the intensity of the immunocytochemical staining and expressed in arbitrary units. Ten sites were measured for each sample. Shown are means \pm SEMs. E-F) Analysis of the PVF collected from embryos at various developmental stages. E) SDS-PAGE. F) Western blot. The gel was stained with Coomassie brilliant blue; immunoblotting was performed with an antiserum against recombinant cystatin. Cystatin is indicated by an arrow. Ten microliters of PVF was loaded for each lane except lane 1 of $\mathbf{F}$, in which $0.2 \mu \mathrm{l}$ of PVF was loaded.

FIG. 5. Agglutination of spermatozoa by the PVF, cystatin, and other proteins. A) PVF (1:1 dilution) from embryos at 10-30 min after fertilization. B) Cystatin isoform $2(250 \mu \mathrm{g} / \mathrm{ml})$ from ovulated eggs. C) Cystatin isoform $2(40 \mu \mathrm{g} / \mathrm{ml})$ from the CM. D) Histone type IV fraction $(2 \mu \mathrm{g} / \mathrm{ml})$. E) Cytochrome c $(80 \mu \mathrm{g} / \mathrm{ml})$. F) BSA $(300 \mu \mathrm{g} /$ $\mathrm{ml})$. Bar $=10 \mu \mathrm{m}$.

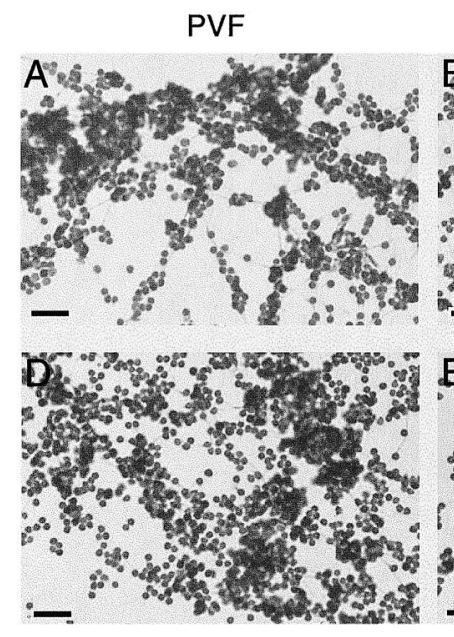

Histone
Egg Cys
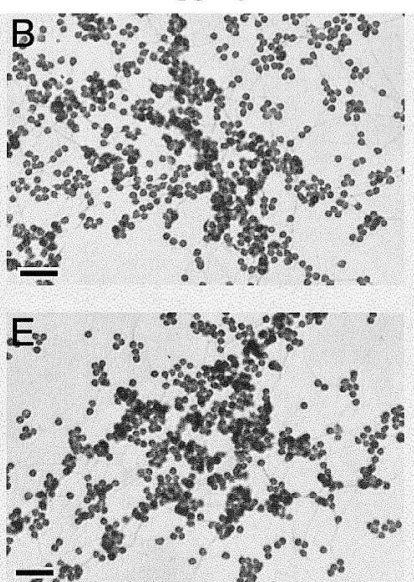

Cytochrome c
CM Cys



$F^{*}: \therefore \circ \circ \therefore \circ \div$

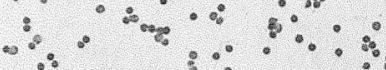

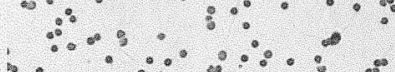

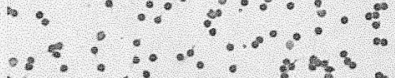

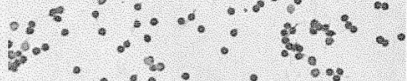


A

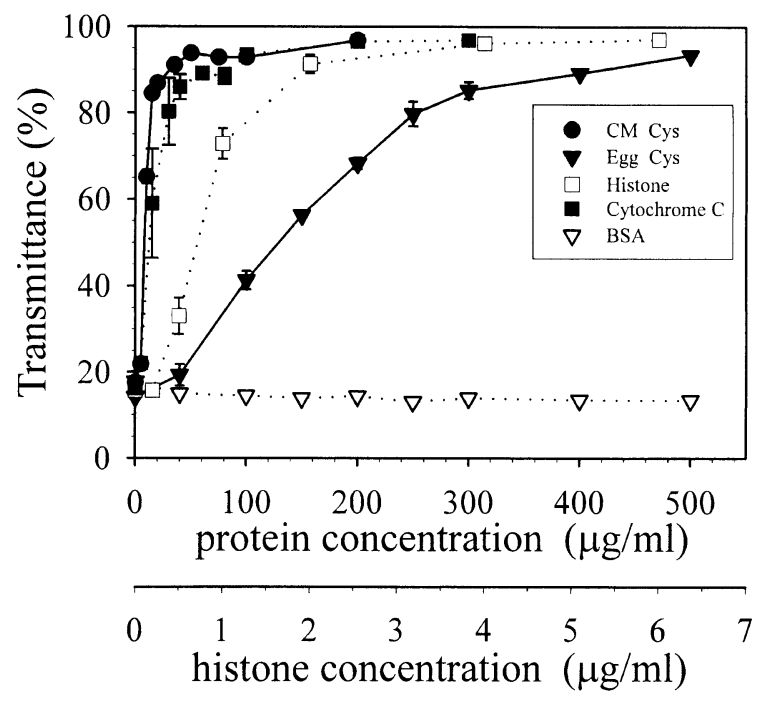

B

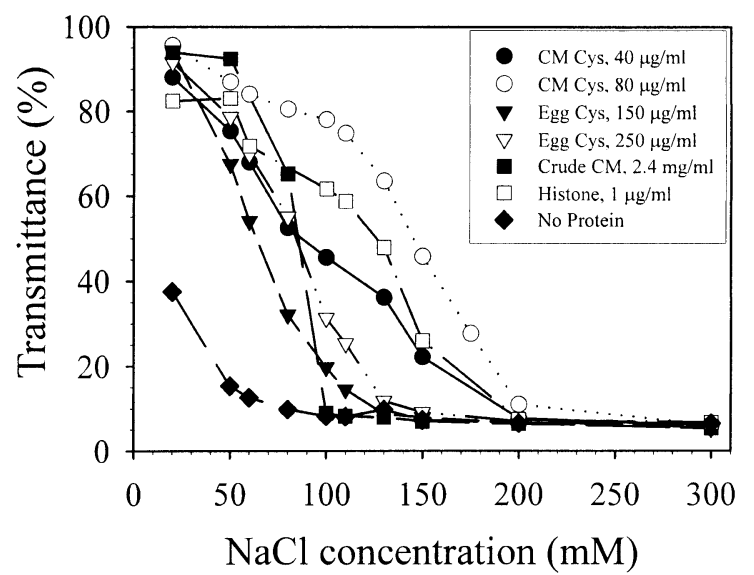

C

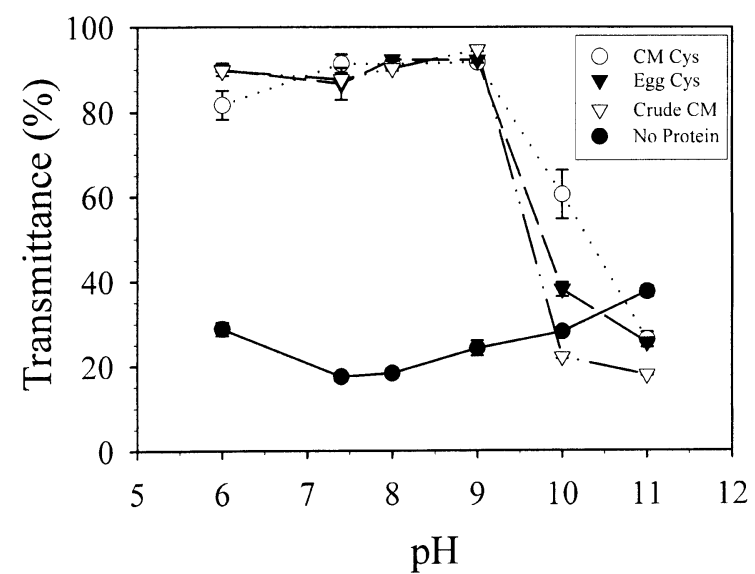

FIG. 6. Effects of protein concentration, salt concentration, and $\mathrm{pH}$ on spermatozoa agglutination. A) Effects of the protein concentration. Note that the scale for histone is different from that of the other proteins. B) Effects of the $\mathrm{NaCl}$ concentration. The assay media contained $10 \mathrm{mM}$ Tris$\mathrm{HCl}(\mathrm{pH} \mathrm{7.4)}$ and varying concentrations of $\mathrm{NaCl}$ as indicated. C) Effects of $\mathrm{pH}$. The amounts of the protein used were $40 \mu \mathrm{g} / \mathrm{ml}$ of cystatin isoform 2 of CM, $250 \mu \mathrm{g} / \mathrm{ml}$ of cystatin isoform 2 of egg, and $2.4 \mathrm{mg} / \mathrm{ml}$ of crude $\mathrm{CM}$. The following buffers in $10 \mathrm{mM}$ concentration and containing 50 $\mathrm{mM} \mathrm{NaCl}$ were used for the assay: 2 -( $\mathrm{N}$-morpholino)ethanesulfonic acid (MES), $\mathrm{pH} 5.0$ and 6.0; Tris- $\mathrm{HCl}, \mathrm{pH} 7.4$ and 8.0; glycine, $\mathrm{pH} 9.0$ and
TABLE 2. Effects of salt concentration and $\mathrm{pH}$ of the assay media on the sperm-agglutinating activity of PVF. ${ }^{a}$

\begin{tabular}{cc}
\hline & Agglutinating activity \\
\hline $\mathrm{NaCl}(\mathrm{mM})$ & \\
0 & +++ \\
50 & -+ \\
150 & - \\
300 & \\
$\mathrm{pH}$ & +++ \\
6 & ++ \\
7.4 & ++ \\
8 & ++ \\
9 & ++ \\
10 & - \\
\hline 1 & \\
\hline
\end{tabular}

a PVF was collected from embryos at 10-30 min after fertilization and diluted 1:9 in various saline buffers. Ten millimolar Tris- $\mathrm{HCl}(\mathrm{pH} 7.4)$ containing various concentrations of $\mathrm{NaCl}$ and $20-\mathrm{mM}$ concentrations of buffers of various $\mathrm{pH}$ containing $50 \mathrm{mM} \mathrm{NaCl}$ were used to assay the effects of salt and $\mathrm{pH}$, respectively, on the sperm-agglutinating activities of the PVF. The following buffers were used: MES, pH 5.0 and 6.0 ; Tris- $\mathrm{HCl}, \mathrm{pH}$ 7.4 and 8.0; glycine, $\mathrm{pH} 9.0$ and 10.0; disodium hydrogen phosphate, $\mathrm{pH} 11.0$.

b Undetectable.

\section{Carp Cystatin Agglutinates the Spermatozoa of Other Species of Fish}

Goldfish spermatozoa were agglutinated by carp cystatin as effectively as carp spermatozoa. The agglutination of goldfish spermatozoa by carp cystatin was also affected by the ionic strength of the assay medium. The $[\mathrm{NaCl}]_{50}$ for $40 \mu \mathrm{g} / \mathrm{ml}$ of isoform 2 cystatin of the CM was $80 \mathrm{mM} \mathrm{NaCl}$ when tested on goldfish spermatozoa, which was comparable to that tested on carp spermatozoa. Carp cystatin also agglutinated tilapia spermatozoa, but a much higher dose was required $(250$ vs. $8 \mu \mathrm{g} / \mathrm{ml}$ of CM cystatin isoform 2 for tilapia vs. carp spermatozoa, respectively). To agglutinate tilapia spermatozoa, the $\mathrm{NaCl}$ concentration was kept below $10 \mathrm{mM}$. Carp cystatin did not agglutinate uncapacitated or capacitated mouse spermatozoa.

\section{Characterization of Sperm-Agglutinating Activity of PVF and $C M$}

As noted earlier, both PVF and CM agglutinated carp spermatozoa. Their sperm-agglutinating activities were influenced by the salt concentration and the $\mathrm{pH}$ of the assay medium. The PVF of the eggs at 10-30 min postfertilization had less activity when diluted with $50 \mathrm{mM} \mathrm{NaCl}$ than when diluted with distilled water. The PVF could not agglutinate spermatozoa in the presence of $150 \mathrm{mM} \mathrm{NaCl}$. The sperm-agglutinating activity of PVF was constant when assayed in media with $\mathrm{pH}$ 6-10, but no activity was detected when the $\mathrm{pH}$ was elevated to 11 (Table 2). As shown in Figure 6B, the sperm-agglutinating activity of the $\mathrm{CM}$ decreased as the salt concentration increased. The CM had a constant sperm-agglutinating activity when assayed in media at $\mathrm{pH}$ 6-9, but the activity was abolished when the $\mathrm{pH}$ was elevated to 10 (Fig. 6C). Apparently, the action of PVF and CM in agglutinating spermatozoa was very sim-

10.0; and disodium hydrogen phosphate, $\mathrm{pH}$ 11.0. The agglutination of spermatozoa was assayed by the method of transmittance of sperm suspension as described in Materials and Methods. Shown in $\mathbf{A}$ and $\mathbf{C}$ are means \pm SEMs of three assays. 
FIG. 7. Immunolocalization of the cystatin binding sites on the surface of spermatozoa. Carp spermatozoa were mixed with $40 \mu \mathrm{g} / \mathrm{ml}$ of cystatin isoform 2 isolated from $\mathrm{CM}$ in $10 \mathrm{mM}$ Tris- $\mathrm{HCl}(\mathrm{pH} 7.4) \mathrm{con}-$ taining $50 \mathrm{mM} \mathrm{NaCl}$ (A) or $200 \mathrm{mM} \mathrm{NaCl}$ (B). After the spermatozoa were fixed with formalin vapor, the bound cystatin was reacted with an antiserum against recombinant cystatin. Signals were revealed by incubation with a TRITC-conjugated second antibody. Different spermatozoa associations are noted, including head-head association $(\mathrm{h}-\mathrm{h})$, head-tail association $(\mathrm{h}-\mathrm{t})$, and tail-tail association (t-t). Bars $=4 \mu \mathrm{m}$.
A

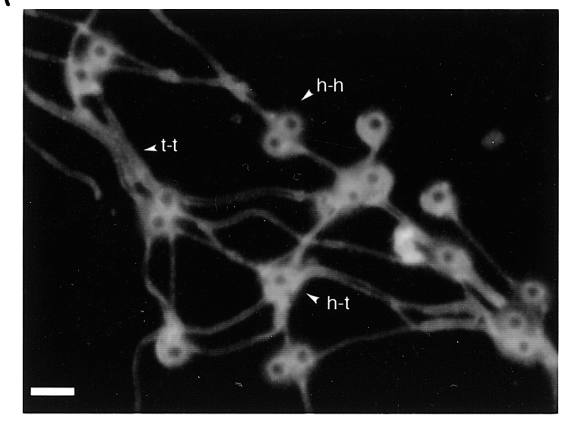

B

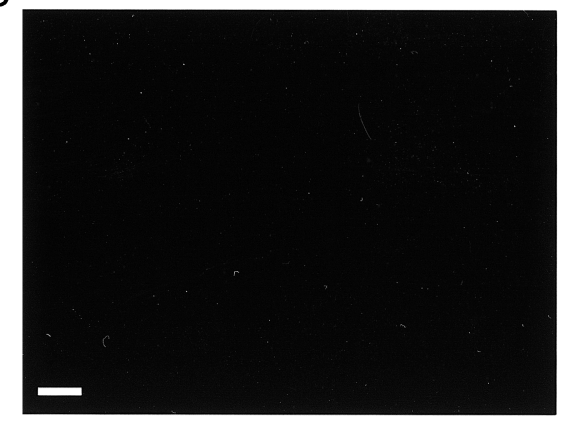

ilar to that of cystatin. These results suggest that cystatin is the major sperm-agglutinating factor of the PVF and CM.

\section{Binding Sites of Cystatin on the Surface of Spermatozoa}

Binding of cystatin to sperm was determined by immunocytochemical localization. As shown in Figure 7A, cystatin signals were seen along the entire surface of the spermatozoa after adding cystatin to the spermatozoa. On the other hand, no cystatin signals were detected on the spermatozoa when the cystatin and spermatozoa were incubated in medium containing $200 \mathrm{mM} \mathrm{NaCl}$ (Fig. 7B). In the presence of cystatin, the spermatozoa were associated in a network fashion. Various associations were observed, including head-to-head, head-to-tail, and tail-to-tail associations (Fig. 7A).

\section{DISCUSSION}

In the present study, we identified cystatin as a spermagglutinating factor. Its action on spermatozoa agglutination was very rapid. Cystatin was discharged from cortical granules into PVS immediately after fertilization. The cystatin content of PVF reached a peak 5 min after fertilization and then declined gradually to the basal level (Fig. 4D). The sperm-agglutinating activity of PVF was related to cystatin concentration. The presence of a large amount of cystatin in PVS $(650 \mu \mathrm{g} / \mathrm{ml}$ of PVF collected from embryos 10-30 min postfertilization) may account for the finding reported by other investigators that PVF can agglutinate fish spermatozoa and that spermatozoa aggregates are found in PVS $[4,10,15,23]$. Therefore, we consider cystatin to be the major sperm-agglutinating factor in PVF.

Cystatin is a basic protein. Other basic proteins, such as histone and cytochrome c, agglutinated carp spermatozoa as well. Their activities were related to their $\mathrm{pIs}$ and were influenced by the ionic strength and the $\mathrm{pH}$ of the assay medium (Fig. 6). It was also noted that the spermatozoa aggregate induced by cystatin was instantly dissociated by $150 \mathrm{mM}$ $\mathrm{NaCl}$. These results suggest that the actions of cystatin on spermatozoa agglutination are mediated through an electrostatic interaction between the positive charges of cystatin and the negative charges of the spermatozoa components.

Kudo and Inoue [24] isolated a sperm-agglutinating factor from the carp fertilization envelope (FE), the activities of which were inhibited by sialic acid, a negatively charged carbohydrate. They proposed that agglutination of spermatozoa induced by the FE factor was mediated by a lectincarbohydrate interaction. The nature of the FE factor has not been identified yet. We do not know whether it is cystatin. We also found that the sperm-agglutinating activity of cystatin was inhibited by heparin (data not shown). How- ever, we do not believe that the action of cystatin on sperm agglutination is mediated through a lectin-carbohydrate interaction as proposed by Kudo and Inoue [24] for the FE factor. The interaction of lectin and carbohydrate were not affected by $150 \mathrm{mM} \mathrm{NaCl}$, but the sperm-agglutinating activities of cystatin and PVF were totally inhibited by 150 $\mathrm{mM} \mathrm{NaCl}$ (Fig. 6 and Table 2). Heparin is a negatively charged carbohydrate, so it might compete with spermatozoa components to bind cystatin. Therefore, the activity of cystatin in agglutinating spermatozoa was inhibited. If the action of cystatin on spermatozoa agglutination was mediated via electrostatic interaction, then the sperm-agglutinating activity of cystatin is not species-specific; that is, carp cystatin can agglutinate spermatozoa of other species of fish. Indeed, this is the case. In addition to agglutinating carp spermatozoa, carp cystatin can agglutinate the spermatozoa of goldfish and tilapia. Like cystatin, carp PVF agglutinates spermatozoa from a variety of species of teleost [25]. This finding is consistent with the postulate that cystatin is the major sperm-agglutinating factor in PVF.

Electrostatic interaction is involved in assembling the myelin sheath of neural tissues [26]. The main protein of the myelin sheath is myelin basic protein (MBP), which electrostatically binds acidic lipids, such as phosphatidylglycerol, phosphatidylserine, and acidic glycosphingolipid [27], to form the multilayered myelin sheath [28, 29]. The aggregation by MBP of acidic lipid vesicles is affected by ionic strength [30, 31], as found in the case of sperm agglutination by cystatin (Fig. 6). The natures of the carp spermatozoa components that bind cystatin are not known yet. The results of the immunocytochemical localization demonstrate that cystatin binds to the entire surface of spermatozoa. This result is consistent with the finding that carp spermatozoa appear in a head-to-head, head-to-tail, and tailto-tail associations after exposure to cystatin (Fig. 7). Similar associations of trout spermatozoa are also induced by the PVF of trout eggs [15, 23]. The components of carp spermatozoa responsible for cystatin binding are currently being investigated.

The corresponding cystatin isoforms isolated from the $\mathrm{CM}$ and eggs had identical molecular weights and partial $\mathrm{N}$-terminal amino acid sequences and the same amount of basic charges, as inferred from their retention time on the cation exchanger column (Fig. 2, A, C, and E). It has been demonstrated that the retention time of a protein on the cation exchanger column reflects the positive charges and the charge distribution of the protein [32]. Therefore, the corresponding cystatin isoforms from the CM and eggs should have the same chemical structures. However, the cystatin isolated from the CM had a much higher spermagglutinating activity than that isolated from the eggs. 
These findings suggest that the number of positive charges is not the sole determinant of the sperm-agglutinating activity of cystatin. Far-UV circular dichroism analysis revealed that the cystatin isolated from the ovulated eggs had a higher helix content than the cystatin isolated from the CM (Fig. 2D). In addition, we found that the cystatin of the eggs and CM had different susceptibilities to trypsin, suggesting that they have different conformations. Therefore, the conformation of cystatin could profoundly affect its sperm-agglutinating activity. We do not know the mechanisms by which the conformation of cystatin is changed during exocytosis and how the conformation affects the sperm-agglutinating activity of cystatin. It is likely that the different conformations of cystatin expose different numbers of positive charges or contacts the negative charges of spermatozoa components differentially.

The specific activity of the cystatin from eggs decreased after purification by cation exchanger column chromatography (Table 1), probably because of the removal of the histone that had a much higher sperm-agglutinating activity than cystatin (Fig. 6). The cystatin prepared from the eggs was more easily contaminated by the histone than that prepared from the CM because cystatin and histone coexisted in the eggs but not in the CM.

Polyspermy is disastrous to embryonic development, so it should be prevented. In carp, prevention of polyspermy is achieved using at least three mechanisms. These mechanisms are 1) limiting by the micropyle of the number of spermatozoa that enter the PVS [4], 2) plugging the micropyle transiently with a fertilization cone that prevents additional spermatozoa from entering the egg [4, 14], and 3) agglutinating the supernumerary spermatozoa by PVF. To prevent polyspermy, the fertilizability of spermatozoa should be eliminated as quickly as possible. Agglutination of spermatozoa by cystatin is an effective measure for this purpose. A large quantity of cystatin is discharged into PVS during the early phase of fertilization (Fig. 4). Cystatin binds to the entire surface of spermatozoa. The electrostatic interaction between cystatin and spermatozoa causes spermatozoa to agglutinate rapidly. Because of the presence of a high concentration of cystatin in the PVF of early embryos and the rapid action of cystatin on spermatozoa agglutination, PVF takes over the function of the fertilization cone in preventing polyspermy during the early phase of fertilization. The action of PVF in inducing spermatozoa agglutination lasts at least $30 \mathrm{~min}$ after fertilization. This notion is consistent with the earlier findings of agglutination of spermatozoa in the PVS of carp eggs during the early stage of fertilization [4] and the occurrence of polyspermia in corticalreacted eggs of trout once the PVF is washed off [15]. In conclusion, the available data indicate that polyspermy in carp is prevented by two different mechanisms in which the chorion, micropyle, and fertilization cone act as physical barriers to limit the number of spermatozoa entering the egg and cystatin electrostatically abolishes the fertilization ability of supernumerary spermatozoa.

\section{REFERENCES}

1. Hagiwara S, Jaffe LA. Electrical properties of egg cell membranes. Annu Rev Biophys Bioeng 1979; 8:385-416.

2. Jaffe LA, Gould M. Polyspermy preventing mechanisms. In: Metz CB, Monroy A (eds.), Biology of Fertilization. Orlando: Academic Press; 1985: 223-250.

3. Wassarman PM. Mammalian fertilization: molecular aspects of gamete adhesion, exocytosis, and fusion. Cell 1999; 96:175-183.

4. Kudo S. Sperm penetration and the formation of a fertilization cone in the common carp egg. Dev Growth Differ 1980; 22:403-414.

5. Nagahama Y. The functional morphology of teleost gonads. In: Hoar
WS, Randall DJ, Donaldson EM (eds.), Fish Physiology, vol. IX(A). Orlando: Academic Press; 1983: 223-275.

6. Laale HW. The perivitelline space and egg envelopes of bony fishes: a review. Copeia 1980; 1980: 210-226.

7. Iwamatsu T, Ohta T. Electron microscopic observation on sperm penetration and pronuclear formation in the fish egg. J Exp Zool 1978; 205:157-180.

8. Ohta T. Electron microscopic observations on sperm entry and pronuclear formation in naked eggs of the rose bitterling Rhodeus ocellatus ocellatus in polyspermic fertilization. J Exp Zool 1985; 234:273-282.

9. Bern O, Avtalion RR. Some morphological aspects of fertilization in Tilapias. J Fish Biol 1990; 36:375-382.

10. Iwamatsu T, Ohta T. Scanning electron microscopic observation on sperm penetration in teleostean fish. J Exp Zool 1981; 218:261-277.

11. Iwamatsu T, Onitake K, Yoshimoto Y, Hiramoto Y. Time sequence of early events in fertilization in the medaka egg. Dev Growth Differ 1991; 33:479-490.

12. Kobayashi W, Yamamoto TS. Fine structure of the micropylar apparatus of the chum salmon egg, with a discussion of the mechanism for blocking polyspermy. J Exp Zool 1981; 217:265-275.

13. Linhart O, Kudo S. Surface ultrastructure of paddlefish eggs before and after fertilization. J Fish Biol 1997; 51:573-582.

14. Kudo S, Sato A. Fertilization cone of carp Cyprinus carpio eggs as revealed by scanning electron microscopy. Dev Growth Differ 1985; 27:121-128.

15. Ginsburg AS. The block to polyspermy in sturgeon and trout with special reference to the role of cortical granules (alveoli). J Embryol Exp Morphol 1961; 9:173-190.

16. Tsai YJ, Chang GD, Huang CJ, Chang YS, Huang FL. Purification and molecular cloning of carp ovarian cystatin. Comp Biochem Physiol 1996; 113B:573-580.

17. Chang YS, Weng JW, Li CC, Huang FL. Identification of cystatin as a component of carp chorion. Mol Reprod Dev 1998; 51:430-435.

18. Laemmli UK. Cleavage of structural proteins during the assembly of the head of bacteriophage T4. Nature 1970; 227:680-685.

19. Brown JO. A simplified and convenient method for the double-embedding of tissues. Stain Technol 1948; 23:83-89.

20. Green GD, Kembhavi AA, Davies ME, Barrett AJ. Cystatin-like cysteine proteinase inhibitors from human liver. Biochem J 1984; 218: 939-946.

21. Eisenthal R, Cornish-Bowden A. The direct linear plot: a new graphical procedure for estimating enzyme kinetic parameters. Biochem $\mathrm{J}$ 1974; 139:715-720.

22. Smith PK, Krohn RI, Hermanson GT, Mallia AK, Gartner FH, Provenzano MD, Fujimoto EK, Goeke NM, Olson BJ, Klenk DC. Measurement of protein using bicinchoninic acid. Anal Biochem 1985; 150:76-85.

23. Ginsburg AS. Sperm-egg association and its relationship to the activation of the egg in salmonid fishes. J Embryol Exp Morphol 1963; $11: 13-33$

24. Kudo S, Inoue M. Bacterial action of fertilization envelope extract from eggs of the fish Cyprinus carpio and Plecoglossus altivelis. $\mathrm{J}$ Exp Zool 1989; 250:219-228.

25. Kudo S. Polyspermy-preventing mechanisms in fish eggs. In: Inoue S, Shirai T, Egar MW, Aiyama S, Geraudie J, Nobunaga T, Sato NL (eds.), Regeneration and Development. Maebashi: Okada Print; 1988: 395-410.

26. Readhead C, Takasashi N, Shine HD, Saavedra R, Sidman R, Hood L. Role of myelin basic protein in the formation of central nervous system myelin. Ann N Y Acad Sci 1990; 605:280-285.

27. Smith R. Non-covalent cross-linking of lipid bilayers by myelin basic protein: a possible role in myelin formation. Biochim Biophys Acta 1977; 470:170-184.

28. Cheifetz S, Moscarello MA. Effect of bovine basic protein charge microheterogeneity on protein-induced aggregation of unilamellar vesicles containing a mixture of acidic and neutral phospholipids. Biochemistry 1985; 24:1909-1914.

29. ter Beest MB, Hoekstra D. Interaction of myelin basic protein with artificial membranes: parameters governing binding, aggregation and dissociation. Eur J Biochem 1993; 211:689-696.

30. Jo E, Boggs JM. Aggregation of acidic lipid vesicles by myelin basic protein: dependence on potassium concentration. Biochemistry 1995; 34:13705-13716.

31. Boggs JM, Yip PM, Rangaraj G, Jo E. Effect of posttranslational modifications to myelin basic protein on its ability to aggregate acidic lipid vesicles. Biochemistry 1997; 36:5065-5071.

32. Hallgren E, Kalman F, Farnan D, Horvath C, Stahlberg J. Protein retention in ion-exchange chromatography: effect of net charge and charge distribution. J Chromatogr A 2000; 877:13-24. 